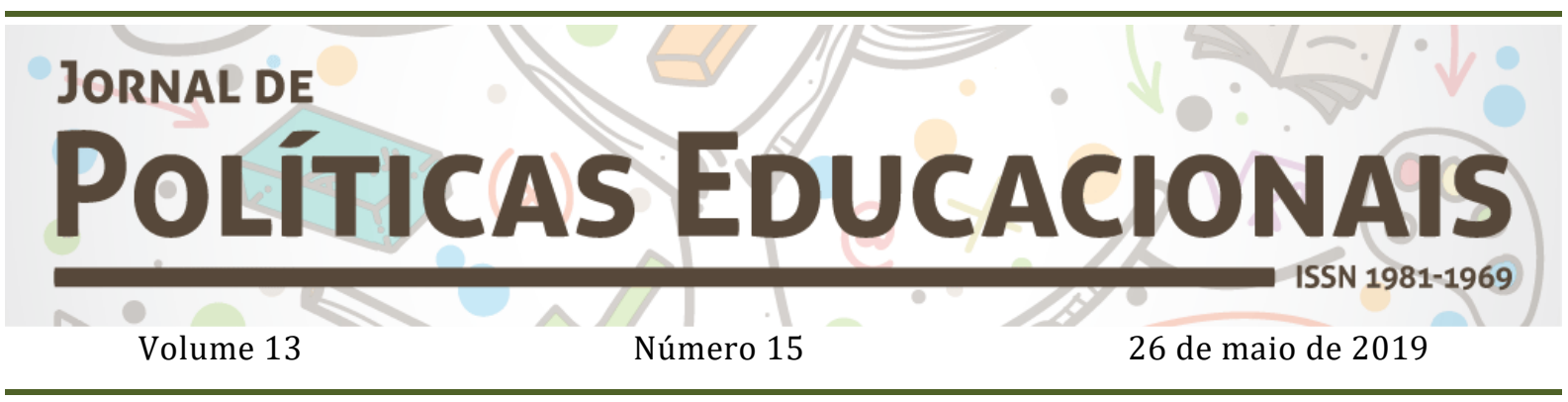

\title{
O plano de ações articuladas e suas influências na gestão da educação municipal: um estado do conhecimento
}

\author{
The articulated plan of action and its influences in the management of \\ municipal education: a state of knowledge
}

\section{El plan de acciones articuladas y sus influencias en la gestión de la educación municipal: un estado del conocimiento}

\author{
Silvana Maria Tres Cichelero ${ }^{1}$
} Elisiane Machado Lunardi²

Citação: CICHELERO, S. M. T.; LUNARDI, E. M. O plano de ações articuladas e suas influências na gestão da educação municipal: um estado do conhecimento Jornal de Políticas Educacionais. V. 13, n.15. Maio de 2019.

\section{Resumo}

Este estudo está vinculado ao Programa de Pós-Graduação em Políticas Públicas e Gestão Educacional, desenvolvido pelo grupo de Pesquisas REDES/CNPQ, da Universidade Federal de Santa Maria (UFSM). É caracterizado como estado do conhecimento e tem como objetivo se inteirar dos estudos realizados referente ao Plano de Ações Articuladas e à Gestão da Educação Municipal a partir de sua implementação. Foi elencando como corpus textual, a BDTD (IBICT). Os descritores da pesquisa são: Plano de Ações Articuladas, Gestão da Educação Municipal, Gestão Democrática e Financiamento da Educação. Foram encontrados 25 trabalhos diferentes. Sendo que, duas dissertações e uma tese correspondiam ao tema investigado, por isso foram analisados aprofundadamente. 0 estudo está fundamentado em uma abordagem quanti-qualitativa, definido como exploratório, descritivo e explicativo. Para o tratamento dos dados foi utilizada a análise de conteúdo. 0 desenvolvimento deste estudo permitiu acessar conhecimentos já construídos sobre o tema de pesquisa, possibilitando

\footnotetext{
${ }^{1}$ Mestre em Políticas Públicas e Gestão Educacional pela Universidade Federal de Santa Maria. ORCID: http://orcid.org/0000-0001-6878-3812 E-mail: syl.tres@gmail.com.

2 Prof.a Orientadora: Doutora em Educação. Professora Adjunta da Universidade Federal de Santa Maria no Departamento de Administração Escolar - UFSM. ORCID: http://orcid.org/0000-0002-2276-2466. Email:elisiane.lunardi@gmail.com
} 

gestão da educação municipal: um estado do conhecimento

concluir que o Plano de Ações Articuladas se configura em uma tentativa de efetivar o regime de colaboração entre os entes federados. Contudo, pela forma centralizadora como foi projetado, implantado e implementado, acabou por se consolidar em um mecanismo híbrido de gestão. Pois quem planeja e determina os meios para sua efetivação é a esfera federal, sem considerar a especificidades das demais esferas, cabendo a elas a execução e responsabilidade pelas ações. Palavras-chave: Plano de Ações Articuladas, Gestão da Educação Municipal, Gestão Democrática, Regime de Colaboração.

\begin{abstract}
This study is linked to the Postgraduate Program in Public Policies and Educational Management, developed by the REDES/CNPQ Research Group at Federal University of Santa Maria (UFSM), Brazil. It is characterized as a state of knowledge and aims to get acquainted with the studies carried out regarding the Articulated Actions Plan and the Municipal Education Management from its implementation. It was listing as textual corpus, the BDTD (IBICT). The research descriptors are: Articulated Action Plan, Municipal Education Management, Democratic Management and Education Financing. 25 different jobs were found. Being that, two dissertations and one thes is corresponded to the subject investigated, reason why they were analyzed in depth. The study is based on a quantitative-qualitative approach, defined as exploratory, descriptive and explanatory. For the data treatment, the content analysis was used. The development of this study allowed access to knowledge already built on the subject of research, making it possible to conclude that the Plan of Articulated Actions is configured in an attempt to effect the collaboration regime among the federated entities. However, due to the centralized way in which it was designed, implemented it was consolidated in a hybrid management mechanism because who plans and determines the means for its realization is the federal sphere, without considering the specificities of the other spheres, and it falls to them the execution and responsibility for the actions.
\end{abstract}

Keywords: Articulated Action Plan, Municipal Education Management, Democratic Management, Collaboration Regime.

\title{
Resumen
}

Este estudio está vinculado al Programa de Postgrado en Políticas Públicas y Gestión Educativa, desarrollado por el grupo de Investigaciones REDES/CNPQ de la Universidad Federal de Santa María (UFSM), Brasil. Se caracteriza como estado del conocimiento y tiene como objetivo enterarse de los estudios realizados referente al Plan de Acciones Articuladas y la Gestión de la Educación Municipal a partir de su implementación. En el marco de la investigación, Los descriptores de la investigación son: Plan de Acciones Articuladas, Gestión de la Educación Municipal, Gestión Democrática y Financiamiento de la Educación. Se han encontrado 25 trabajos diferentes. Siendo que, dos disertaciones y una tesis correspondían al tema investigado, y por eso fueron analizados en profundidad. El estudio está fundamentado en un abordaje cuantitativo, definido como exploratorio, descriptivo y explicativo. Para el tratamiento de los datos se utilizó el análisis de contenido. El desarrollo de este estudio permitió acceder a conocimientos ya construidos sobre el tema de investigación, posibilitando concluir que el Plan de Acciones Articuladas se configura en un intento de efectivizar el régimen de colaboración entre los entes federados. Sin embargo, por la forma centralizadora como fue proyectado, implantado e implementado acabó por consolidarse en un mecanismo híbrido de gestión porque quien planea y determina los medios para su efectividad es la esfera federal, sin considerar las especificidades de las demás esferas, correspondiendo a ellas la ejecución y responsabilidad por las acciones.

Palabras clave: Plan de Acciones Articuladas, Gestión de la Educación Municipal, Gestión Democrática, Régimen de Colaboración. 


\section{Introdução}

O Plano de Ações Articuladas (PAR) surgiu trazendo inúmeras dúvidas e incertezas como parte do Plano de Metas Compromisso Todos Pela Educação. No decorrer deste tempo de implantação e implementação do PAR inúmeros questionamentos foram surgindo, entre eles: a legislação determina a gestão democrática da educação, no entanto, o governo federal toma para si a criação de Políticas Públicas, as quais os municípios aderem via PAR, com o objetivo principal de obter recursos financeiros; o PAR é dividido em quatro dimensões: 1 - Gestão Educacional; dimensão 2 - Formação de Professores e de Profissionais de Serviço e Apoio Escolar; dimensão 3 - Práticas Pedagógicas e Avaliação; e dimensão 4 - Infraestrutura Física e Recursos Pedagógicos, no entanto, acaba que a atenção fica voltada quase que exclusivamente para a quarta, já que é aquela que possibilita o recebimento de recursos financeiros; o PAR surgiu como um instrumento metodológico de cooperação entre Município e União, para o planejamento e gestão da educação de forma democrática e participativa, contudo, isso realmente se efetivou?

Partindo dessas indagações, optou-se em elaborar um estado do conhecimento das produções acadêmicas com o objetivo de se inteirar dos estudos já realizados referente ao Plano de Ações Articuladas e a Gestão da Educação Municipal a partir de sua implementação, apresentando o levantamento das produções acadêmicas (dissertações e teses) da base de dados da Biblioteca Digital Brasileira de Teses e Dissertações (BDTD), do Instituto Brasileiro de Informação em Ciência e Tecnologia (IBICT), tendo como descritores: Plano de Ações Articuladas, Gestão da Educação Municipal, Gestão Democrática e Financiamento da Educação. Para tanto, descreve-se os procedimentos metodológicos utilizados no desenvolvimento deste trabalho.

\section{Aspectos Metodológicos}

Este estudo foi desenvolvido no âmbito do Curso de Mestrado Profissional em Políticas Públicas e Gestão Educacional/UFSM e segue a metodologia denominada 'estado do conhecimento', que compreende o levantamento e análise de produções do tema em estudo, de uma única base de dados (ROMANIWSKI e ENS, 2006), tendo por objetivo a "identificação, registro, categorização que levem à reflexão e síntese sobre a produção cientifica de uma determinada área, em um determinado espaço de tempo". (MOROSINI e FERNADES, 2014, p.155). A construção do Estado do Conhecimento a respeito de um 
determinado tema de pesquisa, possibilita o levantamento e a análise do que foi produzido a seu respeito, alicerçando a produção científica a ser construída pelo pesquisador de modo a fundamentá-la e qualificá-la.

A busca foi realizada no mês de março de 2018, determinando-se como filtro o período de defesa de 2008 a 2018. A definição do período a ser analisado levou em consideração o fato de o PAR ter sido criado e implementado no ano de 2007, possibilitando o desenvolvimento de estudos a partir de então. Inicialmente se buscou pelo Descritor Plano de Ações Articuladas/Todos os Campos, o que obteve 7.603 resultados, o que evidenciou a necessidade de especificar a procura, delimitando-a ao tema de pesquisa. Assim, novas buscas avançadas foram realizadas a partir de diferentes descritores e filtros, conforme apresentado no quadro a seguir, tendo sempre o crivo do período de defesa já elencado.

Quadro 1- Parâmetros utilizados na pesquisa

\begin{tabular}{|c|c|c|c|}
\hline & Descritores & Filtros & Resultados \\
\hline 1 & Plano de Ações Articuladas & Assunto & 15 \\
\hline \multirow[t]{2}{*}{2} & Plano de Ações Articuladas & Título & \multirow[t]{2}{*}{17} \\
\hline & Gestão da Educação Municipal & Resumo em Português & \\
\hline \multirow[t]{2}{*}{3} & Plano de Ações Articuladas & Título & \multirow[t]{2}{*}{11} \\
\hline & Gestão Democrática & Resumo em Português & \\
\hline \multirow[t]{2}{*}{4} & Plano de Ações Articuladas & Título & \multirow[t]{2}{*}{03} \\
\hline & Financiamento da educação & Resumo em Português & \\
\hline \multirow[t]{2}{*}{5} & Plano de Ações Articuladas & Título & \multirow[t]{2}{*}{05} \\
\hline & Regime de Colaboração & Resumo em Português & \\
\hline
\end{tabular}

Fonte: Elaborado pelas autoras.

Dos resultados obtidos, foram encontrados 25 (vinte e cinco) trabalhos diferentes. Destes, dois se repetiam na pesquisa de quatro descritores, seis se repetiam em três, nove se repetiam na pesquisa de dois descritores e oito apenas em um dos descritores.

Em seguida foi realizada a leitura flutuante dos resumos das dissertações e teses encontradas, e a sistematização dos dados por: temas de pesquisa; palavras chaves; tipo de documento (dissertação ou tese); Instituição; ano de defesa; Metodologia (tipo de 
CICHELERO, S. M. T.; LUNARDI, E. M. O plano de ações articuladas e suas influências na gestão da educação municipal: um estado do conhecimento

pesquisa, métodos, abordagens, instrumentos e tratamento de dados); Público Alvo, analisando o seu conteúdo.

[...] a análise de conteúdo é um conjunto de técnicas de exploração de documentos, que procura identificar os principais conceitos ou os principais temas abordados em um determinado texto. Ela começa, geralmente, por uma leitura flutuante por meio da qual o pesquisador, num trabalho gradual de apropriação do texto, estabelece várias idas e vindas entre o documento analisado e as suas próprias anotações, até que comecem a emergir os contornos de suas primeiras unidades de sentido. Estas unidades de sentido - palavras, conjunto de palavras formando uma locução ou temas - são definidas passo a passo e guiam o pesquisador na busca das informações contidas no texto (OLIVEIRA, et.al., 2003, p.5-6).

A sistematização dos dados está apresentada nos gráficos a seguir:

Gráfico 1- Número de trabalhos analisados por ano de defesa.

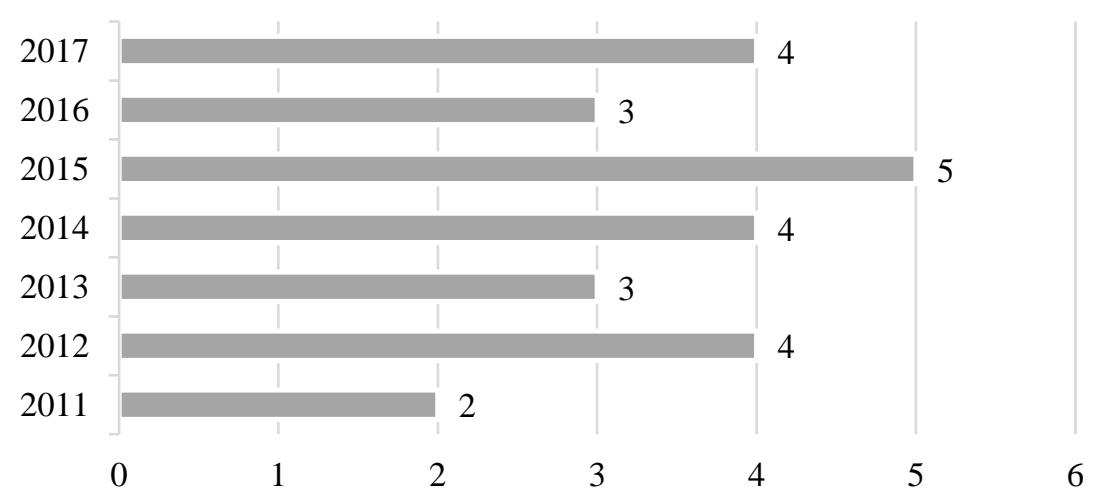

Fonte: Elaborado pelas autoras.

É possível observar que os trabalhos a respeito do PAR começam a aparecer a partir do ano de 2011, acredita-se que isso se deve ao fato de que 2011/2012 se encerrou o primeiro ciclo do PAR 2008/2011. Tornando-se, assim, objeto de análise e estudos científicos. Sendo que, o maior número de pesquisas se deu em nível de mestrado, conforme pode ser observado no gráfico que segue:

Gráfico 2- Tipo de Trabalho

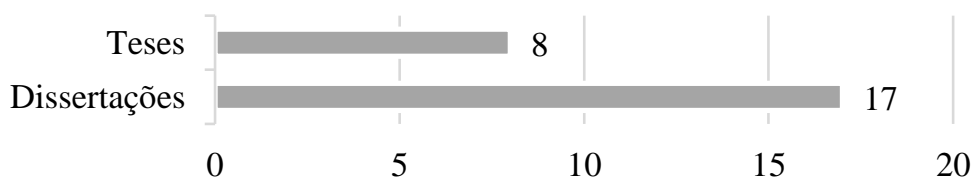

Fonte: Elaborado pelas autoras. 
No gráfico a seguir são apresentadas as universidades pelas quais foram realizados os estudos, são elas: Universidade Federal do Espírito Santo (UFES), Universidade Federal de Juiz de Fora (UFJF), Universidade Federal do Pará (UFPA), Universidade Federal de Pernambuco (UFPE), Universidade Federal de Pelotas (UFPEL), Universidade Federal do Rio Grande do Sul (UFRGS),Universidade Federal de São Carlos (UFSCAR), Universidade Federal de Uberlândia (UFU), Universidade de Brasília (UnB), Universidade Estadual Paulista (UNESP) e Universidade do Vale do Rio dos Sinos (UNISINOS). 0 maior número de trabalhos pertence a Universidade Federal do Pará (UFPA), pois ela mantinha um grupo de pesquisas a respeito do Plano de Ações Articuladas.

Gráfico 3- Instituições de Ensino Superior

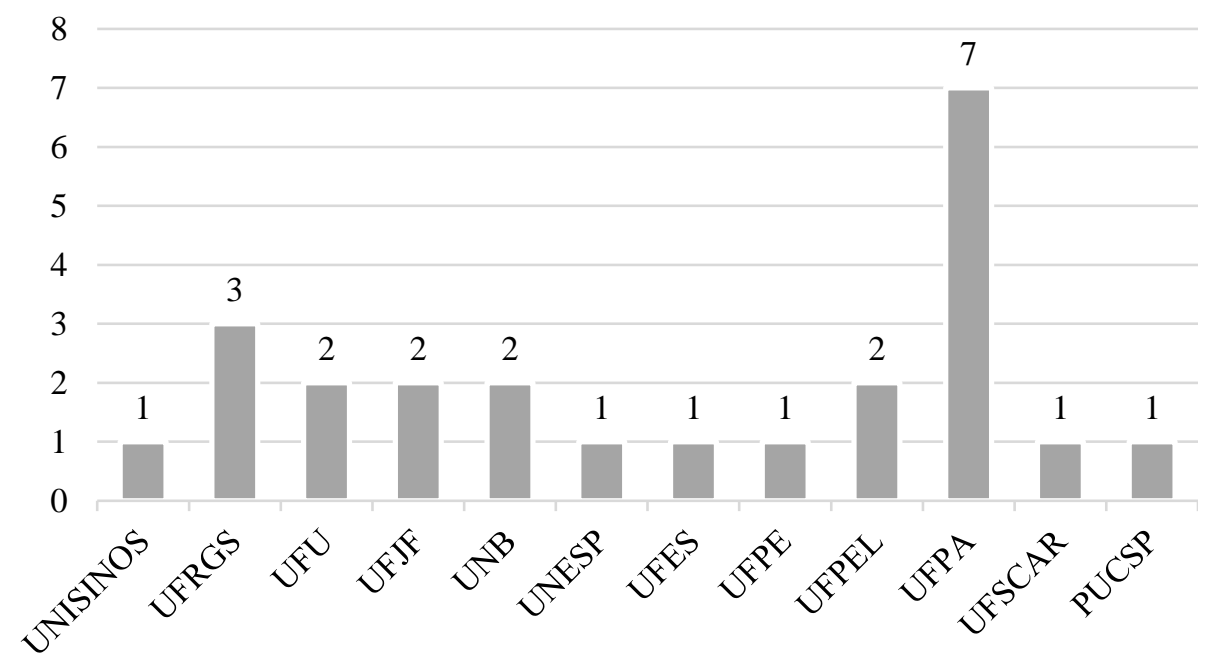

Fonte: Elaborado pelas autoras.

Quanto à metodologia utilizada nos trabalhos analisados prevaleceu a abordagem qualitativa. Os métodos e recursos utilizados constam nos gráficos a seguir: 

gestão da educação municipal: um estado do conhecimento

Gráfico 4- Métodos de Pesquisa

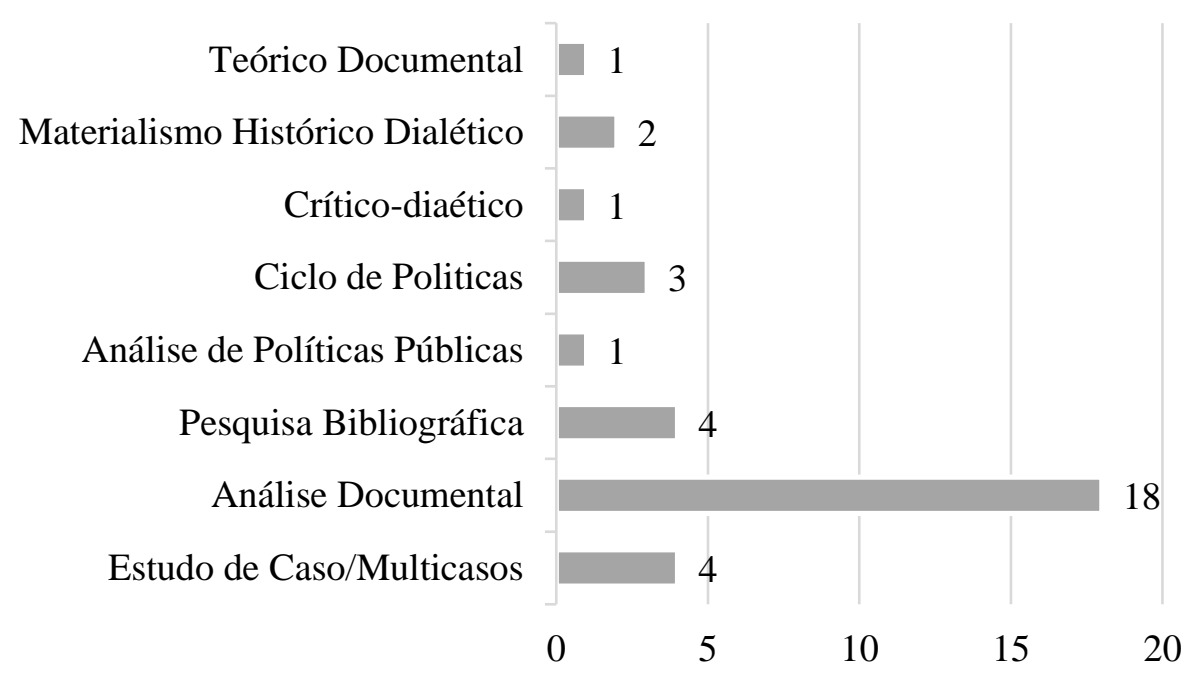

Fonte: Elaborado pelas autoras.

Como observado no gráfico anterior, o método de Análise Documental está presente na grande maioria dos trabalhos, os quais associam a ele um outro método de pesquisa empírica. As entrevistas semiestruturadas e as entrevistas prevalecem como recurso de coleta de dados empíricos.

Gráfico 5- Instrumentos de Pesquisa

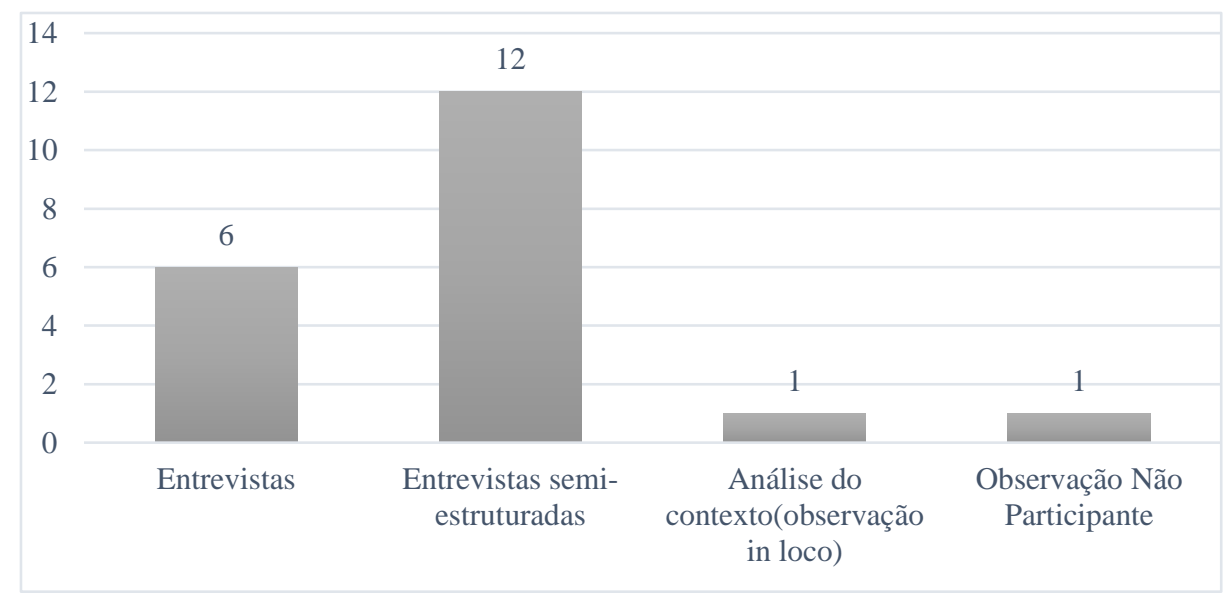

Fonte: Elaborado pelas autoras.

Quanto ao tratamento dos dados foram utilizadas a Análise de Discurso e a Análise de Conteúdo. 0 Público Alvo envolveu os Secretários da Educação, Técnicos responsáveis pelo PAR das Secretarias de Educação, e os membros dos Comitês Gestores do PAR. 
CICHELERO, S. M. T.; LUNARDI, E. M. O plano de ações articuladas e suas influências na gestão da educação municipal: um estado do conhecimento

Quanto aos assuntos pesquisados, 'A implementação do Plano de Ações Articuladas (adesão, elaboração, monitoramento e execução)' foi o tema abordado em $50 \%$ (cinquenta por cento) dos trabalhos. Seguido pela 'Influência e implicações do PAR na Gestão da Educação' e a o 'Regime de Colaboração entre os entes Federados a partir do PAR'. As palavras-chaves mais utilizadas foram: Plano de Ações Articuladas; Políticas Públicas Educacionais; Educação e Estado; Gestão Municipal, da Educação e Democrática; Educação; Planejamento; Sistema Municipal de Educação e Descentralização e Autonomia.

A partir desta sistematização foram selecionados os trabalhos para compor o corpus de análise, considerando os que mais se aproximavam do tema de pesquisa: "A gestão da Educação Municipal a partir da implementação do Plano de Ações Articuladas". Em um primeiro momento foram observados e avaliados sete dos 25 (vinte e cinco) trabalhos. Destes, no entanto, foram selecionados três para a leitura e análise mais aprofundada.

A opção por estes três trabalhos se deu a partir da análise dos sumários e dos resultados da pesquisa dos sete trabalhos, considerando os que mais se aproximam do tema em estudo e, por isso, trarão maior contribuição a este trabalho.

Quadro 2- Trabalhos analisados

\begin{tabular}{|l|l|l|l|l|}
\hline \multicolumn{1}{|c|}{ Título } & \multicolumn{1}{|c|}{ Autor } & \multicolumn{1}{c|}{ Instituição } & Ano & \multicolumn{1}{c|}{ Tipo } \\
\hline $\begin{array}{l}\text { Colaboração Intergovernamental ou } \\
\text { Indução de Ações pela União? } \\
\begin{array}{l}\text { Analisando a Implementação do Plano } \\
\text { de Ações Articuladas (PAR) em } \\
\text { Municípios do Agreste de Pernambuco. }\end{array}\end{array}$ & $\begin{array}{l}\text { Cleciana } \\
\text { Alves De } \\
\text { Arruda }\end{array}$ & $\begin{array}{l}\text { Universidade } \\
\text { Federal De } \\
\text { Pernambuco }\end{array}$ & 2013 & Dissertação \\
\hline $\begin{array}{l}\text { Gestão Educacional no Plano de Ações } \\
\text { Articuladas do Município De Macapá- } \\
\text { AP: Concepções E Desafios. }\end{array}$ & $\begin{array}{l}\text { Ilma De } \\
\text { Andrade } \\
\text { Barleta }\end{array}$ & $\begin{array}{l}\text { Universidade } \\
\text { Federal Do Pará }\end{array}$ & 2015 & Tese \\
\hline $\begin{array}{l}\text { Plano de Ações Articuladas e a Gestão } \\
\text { Educacional do Município de Altamira- } \\
\text { PA. }\end{array}$ & $\begin{array}{l}\text { Raimundo } \\
\text { Sousa }\end{array}$ & $\begin{array}{l}\text { Universidade } \\
\text { Federal Do Pará }\end{array}$ & 2015 & Dissertação \\
\hline
\end{tabular}

Fonte: Elaborada pelas autoras. 


\section{Análise das dissertações e teses}

Para uma análise mais detalhada dos trabalhos selecionados, foram consideradas os aportes metodológicos utilizados, a definição dos problemas/temáticas e resultados das pesquisas, e as considerações finais, buscando, assim, extrair referências sobre os descritores elencados.

Quanto à problematização das pesquisas, os três trabalhos buscam explicitar as influências e implicações do PAR na gestão educacional dos municípios à luz dos preceitos da gestão democrática: participação, descentralização e autonomia.

Quanto aos fundamentos teórico-metodológicos, dois trabalhos, uma dissertação e a tese, apoiam-se no materialismo histórico dialético. "No ato epistêmico sob base do materialismo, sujeito e objeto interagem na perspectiva da práxis, teoria e empiria se apresentam como elementos fundantes no processo epistemológico marxiano" (SOUSA, 2015, p. 24), levando à compreensão da "coisa em si" (KOSIK, apud SOUZA, 2015), ou seja, ultrapassa as aparências na busca da essência. É na relação sujeito e objeto que emerge o novo conhecimento, que, por sua vez não é imutável, mas sim histórico. A outra dissertação, está embasada

[...] na perspectiva crítico-dialética de pesquisa, associada à abordagem de análise de política pública formulada por Muller e Surel (2002), que para além de uma perspectiva sequencial, busca de forma contextualizada apreender os sentidos de que se revesse determinada política enquanto ação do Estado (ARRUDA, 2013, p. 20).

Como métodos utilizados, os três autores (ARRUDA, 2013; BARLETA, 2015; SOUZA, 2015) fizeram uso da pesquisa documental, o que proporcionou que adentrassem no conteúdo dos documentos oriundos da implantação e implementação do PAR, tanto em nível nacional, e principalmente em nível municipal, da pesquisa de campo e estudo de caso, que propiciaram o contanto direto com a instituição a ser estudada. Para tanto, utilizaram-se do recurso das entrevistas semiestruturadas, o que possibilita a captação imediata da informação. Foram entrevistados secretários de educação, membros da Equipe Técnica Local responsável pelo PAR, do Comitê Local do Compromisso Todos Pela Educação e do Conselho Municipal de Educação, além de professores e coordenadores pedagógicos e outros envolvidos na implantação e implementação do Plano nos municípios investigados. 0 tratamento dos dados se deu de forma analítica, através do cruzamento de dados e da Análise do Discurso. 


\section{Análise dos descritores}

A análise dos descritores foi realizada à luz da problemática investigada, ou seja, buscaram-se elementos que evidenciam as implicações do PAR na gestão da educação municipal no que se refere à sua democratização.

Os descritores utilizados para a pesquisa do estado do conhecimento: Plano de Ações Articuladas; Gestão Educacional; Gestão Democrática; Financiamento da Educação; e Regime de Colaboração estão interrelacionados e se complementam na análise proposta por este estudo.

O Plano de Ações Articulada (PAR) pode ser definido como o mecanismo de materialização do Plano de Desenvolvimento da Educação (PDE) que passa a vigorar através do Decreto no 6.094 (BRASIL, 2007), que dispõem sobre a implementação do Plano de Metas Todos pela Educação, num regime de colaboração entre a União e os demais entes federados e a participação das famílias e da comunidade, mediante programas e ações de assistência técnica e financeira, visando a mobilização social na melhoria da qualidade da educação.

O PAR é composto por quatro dimensões: a) gestão educacional; b) formação de professores e profissionais de serviço e apoio escolar; c) recursos pedagógicos e avaliação e; d) infraestrutura física e prática pedagógica; divididas em áreas, indicadores e ações. As Ações e subações de cada dimensão podem ser executadas pelos sistemas municipais e estaduais a partir do diagnóstico da realidade educacional, norteados pela premissa da melhoria do desempenho do Índice de Desenvolvimento da Educação Básica (IDEB) (BARLETA, 2015).

Nessa seara, Arruda (2013) aponta que a oferta da educação formal no território brasileiro, segundo as prerrogativas legais, é de reponsabilidade partilhada entre a União, os estados, o DF e os municípios, tendo como princípio orientador o regime de colaboração. Esta colaboração está amparada pela Constituição Federal (BRASIL, 1988), em seu artigo 211, e na LDBEN (BRASIL, 1996), art. 8º contudo, não são apresentadas uma conceituação e uma descrição definidas.

Diante disto, o governo central vem propondo ações coordenadas e complementares para fortalecer o regime colaborativo entre os entes federados objetivando a melhoria da qualidade educacional. Estas ações, na sua maioria, são 
CICHELERO, S. M. T.; LUNARDI, E. M. O plano de ações articuladas e suas influências na gestão da educação municipal: um estado do conhecimento

organizadas na forma de programas e projetos educacionais de adesão compulsória (PNAE, PNATE, PLI...) e voluntária (Programa Formação pela Escola; PRADIME...).

Nesta esteira, o PAR se configurou numa estratégia expressiva de consolidação do regime de colaboração entre a União e os municípios. No entanto, os estudos de Arruda (2013, p.141) apontam que

[...] a ação colaborativa expressa nessa política, foi marcada predominantemente pela subordinação das municipalidades à esfera central de poder, o que não significa que a colaboração não tenha ocorrido, mas que se revestiu de uma tônica de imposição por parte da esfera central de poder.

A autora destaca três pontos relevantes que corroboram esta ideia: 1) a imposição federal no processo de adesão ao Plano, que foi elaborado sem discutir a realidade educacional local com as instâncias federativas, tomando como base para a sua organização o IDEB, uma avaliação de larga escala que não garante o conhecimento das especificidades educacionais; 2) a tomada dos "resultados deste índice para convocar as municipalidades a aderirem ao Plano e a operacionalizá-lo sem que tenham partilhado diretamente de sua criação" (ARRUDA, p.141) e; 3) a imposição da adesão aos municípios como forma de obter recursos da União, para além daqueles já garantidos constitucionalmente, para assim, buscar atender às fragilidades estruturais e a carência de recursos de suas redes de ensino.

Nesta perspectiva, as pesquisas evidenciam que o Plano de Desenvolvimento da Educação, consolidado pelo PAR, teve sua formulação, elaboração e a definição de sua política, mantidos pelo núcleo estratégico do governo central, ou seja, em nível federal, cabendo aos demais entes federados apenas a sua execução. Desta forma, assume características da gestão gerencial, com foco em metas pré-estabelecidas para a busca de resultados a serem atingidos pelos municípios e estados sob a coordenação da União.

\footnotetext{
A descentralização se dá apenas na execução da oferta educacional, pois o núcleo de decisão se mantém centralizado no âmbito do governo federal. A participação da sociedade e dos sujeitos locais do município assume as feições da responsabilização e a autonomia encontra barreiras para se efetivar, devido às necessidades imediatas do governo local em atender as concepções, diretrizes e metas definidas pelo poder central (BARLETA, 2015, p. 37).
}

Neste cenário, os municípios adeptos ao PAR, seguiram rigorosamente os procedimentos para sua elaboração. Para tanto, foi disponibilizado acesso ao SIMEC, plataforma virtual na qual os dados necessários para o preenchimento do PAR foram abarcados. 0 suporte de orientações foi disponibilizado pelo MEC/FNDE na forma de 
manuais, para os municípios não prioritários, enquanto que os municípios considerados prioritários, em função de sua nota abaixo da média no IDEB, estipulada em 3,8, receberam auxílio de técnicos do MEC/FNDE. Inicialmente foram preenchidos os diagnósticos situacionais que incluíam a pontuação, justificativa e definição de demandas. $\mathrm{Na}$ etapa seguinte, puderam acessar as ações e subações.

Sua estrutura predeterminada simplifica o preenchimento das ações, contudo nega a participação efetiva, pois controla a sua elaboração. Os municípios ficam limitados à elaboração da justificativa, à determinação das demandas e à indicação da pontuação, o que por vezes não reflete a realidade educacional, pois contempla aspectos gerais e não a realidade local.

Desta forma, podemos adentrar a análise de outros dois descritores utilizados na pesquisa: A Gestão Educacional e a Gestão Democrática. Isto porque, analisando a forma como foi implantado e operacionalizado, ficou claro que o PAR

[...] se configura como um hibridismo de gestão para a educação. Sua construção, operacionalização e controle evidenciam aspectos da gestão gerencial, principalmente pela responsabilização por meio dos termos de compromisso e definições de metas a serem alcançadas. Também destaca a importância da democratização da gestão da educação ao reafirmar princípios constitucionais, como a gestão democrática. Enfatiza ainda a importância desse princípio para a organização dos sistemas de ensino, destacando, dentre outras, a criação de conselhos, planos municipais de educação e escolha de diretor escolar (SOUZA, 2015, p. 161).

A primeira Área da Dimensão 1 "Gestão Democrática: Articulação e Desenvolvimento dos Sistemas de Ensino" avalia os indicadores da Gestão Democrática nos sistemas de ensino, responsabilizando os municípios a organizarem sua gestão, implementando os mecanismos de gestão democrática. No entanto, conforme os trabalhos analisados, o Plano de Ações Articuladas, não logrou êxito no que se refere à democratização da gestão, com exceção de que agora há um planejamento.

Isto acontece, pois, os Conselhos que deveriam estreitar as relações entre a sociedade e o Estado, promovendo a participação de todos, acabam se limitando à atuação técnica, ou mesmo figurativa, não provocando o enfrentamento da ordem estabelecida, seja pela inércia de seus membros ou pela capacidade de controle que os governos têm sobre os colegiados, configurando o desinteresse dos governos em implementar e fortalecer a democratização da educação (SOUZA, 2015). 
CICHELERO, S. M. T.; LUNARDI, E. M. O plano de ações articuladas e suas influências na gestão da educação municipal: um estado do conhecimento

Retomando, a ideia de que o PAR, como instrumento de gestão da educação, acaba centralizando as decisões na esfera federal, condicionando os municípios ao papel de executor das ações impostas, Barleta (2015, p.188) reitera:

O modelo de descentralização, autonomia a participação presentes nos indicadores do PAR se apresenta como face de uma estratégia previamente desenhada e definida para “modernizar" a gestão. Para Arretche (1999), tal movimento busca delimitar a atuação do município como forma de inibir possíveis forças promotoras de mudanças, bem como busca responsabilizar os sujeitos que executam a política pelos resultados educacionais obtidos.

Mesmo com este caráter impositivo e centralizador, Arruda (2013) destaca influências positivas do Plano na gestão da educação nos municípios, quais sejam:

- tem representado, de certa forma, um avanço nas relações colaborativas entre os entes federados, principalmente no que se refere à responsabilidade supletiva da União, visto que os municípios receberam maior ajuda financeira;

- quanto à consolidação da gestão educacional local, ressalta a aproximação do MEC e do FNDE dos municípios, que deixam de depender de um político local para intermediar a aprovação de projetos educacionais, pois possibilitou acesso direto aos programa, projetos e recursos do Governo Federal;

- possibilitou às redes de ensino planejar e sistematizar projetos federais e acompanhar o seu desenvolvimento;

- favoreceu a formação de quadros técnicos durante a sua operacionalização.

- pode possibilitar a "alteração da concepção de educação como algo pertencente a determinado grupo político para algo público".

- Por último pontua que:

[...] o caráter multidimensional do Plano oferece possibilidades para que a gestão educacional local aprenda a lidar com uma perspectiva ampla de organização de suas redes, visto que o PAR traz ações e subações a serem operacionalizadas em quatro importantes macrocampos da gestão sistêmica (Gestão educacional, Formação de professores, de profissionais de serviços e apoio escolar, Práticas pedagógicas e avaliação, Infraestrutura e recursos pedagógicos) (ARRUDA, 2013, p.144).

O desenvolvimento deste estado do conhecimento, possibilitou acessar estudos já construídos sobre o tema de pesquisa proposto neste projeto, o que permitiu concluir que o Plano de Ações Articuladas se configurasse em uma tentativa de efetivar o regime de colaboração entre os entes federados. Contudo, pela forma centralizadora como foi projetado, implantado e implementado, acabou por se consolidar em um mecanismo 
híbrido de gestão. Pois quem planeja e determina os meios para sua efetivação é a esfera federal, sem considerar a especificidades e a opinião das demais esferas, cabendo aos demais entes federados a execução e responsabilidade pelas ações.

Mesmo que sejam listados pontos positivos deste plano para a gestão da educação municipal o que fica mais evidente é o poder decisório centralizado nas mãos da união e a subordinação dos municípios ao concretizá-lo. Subordinação esta que não é questionada, principalmente, porque o plano acabou por se torna um meio de ampliar a gama de recursos financeiros a serem aplicados nas esferas municipais tão carentes de infraestrutura.

Para o Ciclo do PAR 2016-2019, foi planejado em conformidade com o Plano Nacional de Educação (PNE), principal ponto de convergência das políticas públicas educacionais para os próximos dez anos. Reiterando em suas diretrizes, metas e estratégias os esforços para materializar um sistema educacional capaz de garantir o direito à educação em sua totalidade (FNDE, 2018). Contudo, cabe ainda analisar como está a conjuntura real deste Plano, considerando o atual contexto econômico, político e social.

\section{Conclusão}

É público e notório que o país passa por um momento de crise política, financeira, moral e ética. E, nesses momentos, os governantes costumam buscar soluções para a crise 'cortando gastos' e limitando programas sociais, ou seja, atingindo quem mais necessita das políticas públicas. E, neste contexto, o Plano de Ações Articuladas foi um dos afetados e, por consequência, a educação nos municípios, que viam neste plano, como foi evidenciado, uma forma de estar mais próximos da esfera federal, pelo menos no que diz respeito à busca direta de recursos para infraestrutura e programas de formação. Tanto que o PAR 2016-2018 ficou inativo até pelo menos a metade do ano de 2017, tendo retornado com um novo leiaute, apresentando modificações significativas na sua organização, aumentando a burocracia e diminuindo os recursos financeiros através dele destinados.

Nesta conjuntura, analisar do Plano de Ações Articuladas, considerando seus objetivos iniciais e a evolução de sua implementação, as modificações incorporadas em suas três versões e as implicações na gestão e na educação dos municípios à luz dos 
CICHELERO, S. M. T.; LUNARDI, E. M. O plano de ações articuladas e suas influências na gestão da educação municipal: um estado do conhecimento

princípios da gestão democrática e da busca pela qualidade da educação se torna ainda mais relevante frente ao contexto político, econômico e social ora apresentado no Brasil.

\section{Referências}

ARRUDA, C.A. Colaboração intergovernamental ou indução de ações pela União? analisando a implementação do Plano de Ações Articuladas (PAR) em municípios do Agreste de Pernambuco. 2013. 154 f. Dissertação (Mestrado) - Universidade Federal de Pernambuco, Recife, 2013. Programa de Pós-Graduação em Educação Disponível em: < https://repositorio.ufpe.br/handle/123456789/12859> Acesso em: mar. 2018.

\section{BARLETA, I. A. A gestão educacional no plano de ações articuladas do município de} Macapá-AP: concepções e desafios. 2015. 218 f. Tese (Doutorado) - Universidade Federal do Pará, Instituto de Ciências da Educação, Belém, 2015. Programa de PósGraduação em Educação. Disponível em:

<http://repositorio.ufpa.br/jspui/handle/2011/8336> Acesso em: mar. 2018.

BRASIL. Congresso Nacional. Constituição da República Federativa do Brasil. Brasília: Senado Federal, Centro gráfico, 1988.

BRASIL. Decreto $\mathbf{n}^{\circ} \mathbf{6 . 0 9 4}$, de 24 de abril de 2007. Plano de Metas Compromisso Todos pela Educação. Brasília, DF, 2007.

BRASIL. Ministério da Educação e Cultura. Lei de Diretrizes e Bases da Educação Nacional. Lei no 9394, de 20 de dezembro de 1996. Dispõe sobre as Diretrizes e Bases da Educação Nacional. Diário Oficial. Brasília, DF: MEC, 1996.

MOROSINI, M.C. e FERNANDES, C. M. B. Estado do Conhecimento: conceitos, finalidades e interlocuções. Educação por Escrito, Porto Alegre, v. 5, n.2, p.154-164, jul.-dez.2014. Disponível em: < file:///C:/Users/User/Downloads/18875-77496-1-PB.pdf> Acesso em: mar. 2018.

OLIVEIRA, E. et. al. Análise de Conteúdo e Pesquisa na Área da Educação. Revista Diálogo Educacional, Curitiba, v.4, n.9, p.11-27, maio. /ago. 2003.

ROMANOWSKI, J. P.; ENS, R. T. As pesquisas denominadas do tipo "estado da arte" em educação. Diálogo Educacional, v. 6, n. 19, p. 37-50, set./dez., 2006.

SOUSA, R. 0 plano de ações articuladas e a gestão educacional do município de Altamira-Pará. 2015. 196 f. Dissertação (Mestrado) - Universidade Federal do Pará, Instituto de Ciências da Educação, Belém, 2015. Programa de Pós-Graduação em Educação. <http://repositorio.ufpa.br/jspui/handle/2011/6712> Acesso em: mar. 2018. 


\title{
JORNAL DE PoLíticas EduCACIONAIS

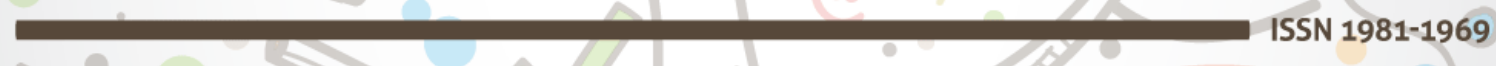 \\ Volume 13 \\ Número 15 \\ 26 de maio de 2019
}

\begin{abstract}
(c)
SORERIGHIS RESERVED O Copyright é retido pelo/a autor/a (ou primeiro co-autor) que outorga o direito da primeira publicação ao Jornal de Políticas Educacionais. Mais informação da licença de CreativeCommons encontram-se em http://creativecommons.org/licenses/by-nc-nd/2.5. Qualquer outro uso deve ser aprovado em conjunto pelo/s autor/es e pelo periódico.

JoRnAL DE POLÍTICAS EdUCACIONAIS é uma publicação do Núcleo de PolíticasEducacionaisdo Setor de Educação da Universidade Federal do Paraná - NuPE/UFPR, em consórcio com a Linha de Pesquisa em Políticas Educacionais do Programa de Pós-Graduação em Educação - PPGE/UFPR, que aceita colaboração, reservando-se o direito de publicar ou não o material espontaneamente enviado à redação. As colaborações devem ser enviadas ao NuPE/UFPR, conforme orientações contidas nas páginas do periódico na internet: http://revistas.ufpr.br/ipe.
\end{abstract}

\author{
Indexação: \\ BBE - Biblioteca Brasileira de Educação (MEC/INEP) \\ Clase (Base de Datos Bibliográfica de Revistas de Ciencias Sociales y Humanidades) \\ Diadorim - Diretório de Política de Acesso Aberto das Revistas Científicas Brasileiras (IBICT) \\ Google Scholar \\ Index Copernicus \\ Portal de Periódicos (CAPES) \\ SER - Sistema Eletrônico de Revistas da Universidade Federal do Paraná (SER/UFPR) \\ Sumários de Revistas Brasileiras (FUNPEC-RP) \\ DRII - Directory of Research Journals Indexing
}

(Periódico integralmente disponível apenas em via eletrônica)

Jornal de Políticas Educacionais / Núcleo de Políticas Educacionais da Universidade Federal do Paraná NuPE/UFPR - v.1, n. 1 (1ํs semestre de 2007) - Curitiba: NuPE/UFPR.

Volume 13, número 15 - Maio de 2019

ISSN 1981-1969

1. Educação - Periódicos. 2. Política Educacional - Periódicos. I. NuPE/UFPR

Comitê Editorial:

Elisângela Scaff (UFPR)

Daniela de Oliveira Pires (UFPR)

Ana Lorena Bruel (UFPR)

Conselho Editorial:

Andréa Barbosa Gouveia (UFPR), Ângela Hidalgo (UNICENTRO), Cesar GernominoTello (Universidad Nacional TresFebrero, Argentina),Gladys Beatriz Barreyro (USP), Juca Gil (UFRGS), Jefferson Mainardes (UEPG), João Ferreira de Oliveira (UFG), Luiz Souza Júnior (UFPB), Marcos Edgard Bassi (UFSC), Regina 
CICHELERO, S. M. T.; LUNARDI, E. M. O plano de ações articuladas e suas influências na gestão da educação municipal: um estado do conhecimento

Maria Michelotto (UFPR), Robert Verhine (UFBA), Rosana Cruz (UFPI), Rubens Barbosa Camargo (USP), Sebastián Donoso Díaz (Universidad de Talca, Chile), Taís Moura Tavares (UFPR), TheresaAdrião (UNICAMP), Vera Peroni (UFRGS).

Créditos e Agradecimentos:

Revisão de Língua Portuguesa, Abstract e Resumen: PROGRAMA DE APOIO ÀS PUBLICAÇÕES CIENTÍFICAS PERIÓDICAS DA UFPR

Arte e diagramação: TIAGO TAVARES (iagotav@gmail.com)

Jornal de Políticas Educacionais

Universidade Federal do Paraná

Setor de Educação

Núcleo de Políticas Educacionais - NuPE/UFPR

Avenida Sete de Setembro, 2645

$2^{\circ}$ andar, Sala 213

80.230-010 - Curitiba - PR - Brasil

Tel.: 41-3535-6264

jpe@ufpr.br

http://revistas.ufpr.br/jpe 